\title{
DOKSOLOGI DALAM TRADISI MANUSKRIP DI NUSANTARA
}

\section{Agul Sulton}

Prodi Pendidikan Bahasa dan Sastra Indonesia

Fakultas Ilmu Pendidikan, Universitas Hasyim Asy’ari Tebuireng, Jombang. surel: agus_sul@yahoo.com

\begin{abstract}
Abstrak
Dalam tradisi pernaskahan Nusantara, doksologi murupakan permulaan teks yang umum digunakan dalam produksi manuskrip-manuskrip Nusantara. Doksologi diletakkan di bagian awal teks yang berisi puji-pujian sebagai bentuk rasa hormat, doa, harapan, puji syukur, dan sebagainya. Dalam penelitian ini akan mengungkap tradisi doksologi yang umum dipakai pada manuskrip-manuskrip di Nusantara. Pada tradisi manuskrip di Nusantara memiliki beragam bentuk, makna, dan fungsi tergantung penulisnya karena ini menyangkut kekuatan iman seseorang atau ketakwaan seseorang terhadap Tuhan. Penulisan doksologi bisa disebut kristalisasi gaya kreatif sang kreator dapat diletakkan pada awal teks dan akhir teks manuskrip. Dalam tradisi tulis dunia modern, doksologi pengertiannya mulai bergeser ke arah ucapan terimakasih dan sumbangsih akan hasil kerja sang pengarang saat melakukan penelitian. Hasil penelitian ini menemukan, penggunaan doksologi yang dulunya ditekankan pujian-pujian terhadap sesuatu yang bersifat dogmatis, namun di era sekarang berkembang ke ruang lingkup pimpinan, lembaga, sahabat, dan keluarga. Secara personal, doksologi merupakan cermin atas sikap religius seseorang, sikap toleransi, kebersamaan, mengasihi sesama, dan intelektualitas manusia.
\end{abstract}

Kata kunci: doksologi, pujian, makna, fungsi, manuskrip

\begin{abstract}
In the Nusantara manuscript tradition, doxology is the beginning of the text that is commonly used in the production of Nusantara manuscripts. Doxology is placed at the beginning of the text which contains praise as a form of respect, prayer, hope, gratitude, and so on. This study will reveal the doxological traditions commonly used in manuscripts in the archipelago. The manuscript tradition in the archipelago has various forms, meanings, and functions depending on the author because it concerns the strength of one's faith or one's devotion to God. Doxology writing can be called crystallization of the creator's creative style can be placed at the beginning of the text and the end of the manuscript text. In the modern world's writing tradition, the doxology of its understanding begins to shift towards acknowledging and contributing to the author's work while conducting research. The results of this study found that the use of doxology which used to emphasize praise for something dogmatic, but in the current era has expanded to the scope of leadership, institutions, friends, and family. Personally, doxology is a reflection of one's religious attitude, tolerance, togetherness, love for others, and human intellect.
\end{abstract}

Keywords: doxology, praise, meaning, function, manuscript

\section{A. PENDAHULUAN}

Hakikat dari manusia adalah makhluk yang lemah. Manusia tidak mampu berbuat apapun tanpa pertolongan Tuhan. Dalam perkembangannya, manusia berperadaban menyadari setiap persoalan selalu mengingatkan dirinya terhadap sesuatu yang dianggapnya luar biasa sebagai penolong atau yang dinilai punya kekuatan magis (Schaik 
p-ISSN: 2301-5926 | e-ISSN: 2579-793X dan Michel, 2016; Clear, 2018). Melakukan pujaan menjadi sangat penting untuk melindungi dirinya agar selamat. Tapak awal ini manusia mulai mempergunakan bentuk pujian-pujian. Pujian dilakukan tidak hanya berbentuk aksara tetapi lebih luas ucapan ritual sesembahan sebelum dimulainya suatu kegiatan atau pekerjaan. Dalam tradisi masyarakat aksara, hal semacam ini dinamakan doksologi.

Agama Islam masuk pertama ke Nusantara abad ke-7 (Puar, 1984: 13) dengan aliran Syi'ah dan Syafi'i ungkapan pujian sudah menjadi suatu kewajiban pada saat itu. Yang menjadi pertanyaan kita saat ini adalah, kapan tradisi penulisan dengan menyebut nama Tuhan (pujian) itu pertama dimulai? Hal ini harus kita kembalikan pada pengertian doksologi itu sendiri. Doksologi dalam Islam tidak ubahnya sebuah doa atau pujian yang ditujukan kepada Allah. Dalam Islam sendiri, doa merupakan suatu anjuran. Allah SWT berfirman:

".....dan barang siapa yang berpaling dari mengingatku (Allah), maka sesungguhnya baginya penghidupan yang sempit dan kami akan menghimpunnya pada hari kiamat dalam keadaan buta. (Thaha: 124)

Berdasarkan pada ayat di atas, dapat ditarik kesimpulan bahwa orang yang memalingkan diri dari mengingat Allah, akan ditindih kesengsaraan yang amat berat. Mungkin dari sini bisa dijadikan acuan tersendiri bahwa memuji kepada Allah merupakan suatu doa (harapan). Dalam kitab al-Kafi di jelaskan, doa adalah otaknya ibadah dan amal yang paling disukai oleh Allah (Mashahiri, 2002: 3). Dari perisai tersebut mugkin dapat dijadikan inovasi tersendiri bagi kepenulisan kitab-kitab Islam oleh kaum mukmin di negara-negara Arab. Sempat disinggung Hashim (2004), gaya penulisan doksologi yang terdapat di dunia Arab Islam telah diteladani oleh penulis-penulis Islam Nusantara. Dengan demikian, Islam masuk ke Nusantara turut masuk pula perbendaharaan kata-kata Arab (Dipodjojo, 1986: 24).

Dalam beberapa manuskrip Islam (naskah keagamaan), yaitu berupa kitab bermakna "jenggotan" yang sekarang sudah banyak dicetak ulang. Di dalam teks manuskrip-manuskrip tersebut-banyak diketemukan doksologi, baik di permulaan penulisan maupun pada akhir penulisan teks. Pemakaian doksologi dalam kepenulisan kitab-kitab bernafaskan Islam sudah seperti suatu keharusan tersendiri bagi pengarang kitab. Hashim (2004) menjelaskan, bahwa dalam karya kitab Islam yang ditulis di Nusantara, doksologi adalah suatu kemestian. Hal ini, tidak lepas dari makna dan fungsi 

dari penulis (pengarang) itu sendiri dalam menghasilkan sebuah karya, maka dari itu di beberapa manuskrip-manuskrip Islam dan manuskrip beraksara Jawa mendapati beberapa variasi doksologi.

Tradisi tulis aksara Jawa, doksologi (purwastrotra) bukan merupakan istilah baru, pemakainan tersebut sudah dimulai pada masa batu bertulis (baca Prasasti Harinjing) dan beberapa karya pujangga Majapahit, seperti Mpu Prapanca dengan kitab Negarakertagama. Termasuk dalam Kakawin Ramayana, Kakawin Bharatayuddha, Serat Pararaton, Sasanasunu, Serat Burat Arum, Serat Arjunasasrabahu dan sebagainya.

Berdasarkan latar belakang di atas, penelitian ini akan membahas mengenai beberapa manuskrip keagamaan Islam untuk melihat bentuk doksologi yang digunakan. Dari beberapa bentuk doksologi yang digunakan tersebut, maka akan diperoleh suatu pemahaman baru mengenai makna dan fungsi doksologi, serta pentingnya kajian doksologi pada telaah manuskrip.

\section{B. KAJIAN TEORI}

Istilah doksologi bermula dari kata Yunani "doxo" yang berarti kemuliaan atau pujian dan "logos" berarti firman. Jadi doksologi secara harfiah berarti kemuliaan firman. Ini mengandung pengertian bahwa puji-pujian kepada Allah dan Nabi Muhammad sebagai rasa syukur atau do'a atas ridho dan sifat kebesaran-Nya. Lebih luas lagi, doksologi merupakan ungkapan pujian kepada Tuhan. Virginia Matheson Hooker (dalam Hashim, 2004) mendefinisikan bahwa doksologi merupakan sholawat dan salam serta salasilah. Selanjutnya Yusof Hashim berpendapat, bahwa doksologi adalah puji-pujian kepada Allah SWT dan Sholawat atas Nabi besar Muhammad SAW.

Doksologi bisa diartikan sebuah hymne. Dalam tradisi Kristen doksologi atau pujian (nyanyian) digunakan pada saat akhir kebaktian. Sedangkan dalam pengetahuan sastra Jawa kuno, Dojosantosa mengartikan doksologi mempunyai persamaan arti dengan kata purwastrotra yang berarti nyanyian pujian atau pujaan permulaan.

Persoalan doksologi diberbagai manuskrip mendapati makna dan fungsi tertentu. Tergantung bagaimana penulis itu mencurahkan pesan puji syukur pada sesuatu yang dianggapnya bagian dari pedoman hidup atau pandangan hidup. Hasyim (2004) mengatakan doksologi berkaiterat dengan kepakaran, latar belakang, serta kedudukan penulis manuskrip. Berdasarkan landasan teori doksologi tersebut, maka peneliti akan 
p-ISSN: 2301-5926 | e-ISSN: 2579-793X menganalisis beberapa manuskrip keagamaan, yakni kitab Bahjatul Ulum, Fathul Mubin, dan Syi'ir Kanjeng Nabi dari sisi makna dan fungsi doksologi yang digunakan.

\section{METODE PENELITIAN}

Penelitian ini menggunakan metode penelitian berjenis library reseach (telaah pustaka). Objek utama atau sumber data primer penelitian ini adalah tiga manuskrip koleksi Adrika Aini di daerah Jombang. Adapun tiga manuskrip tersebut adalah kitab Bahjatul Ulum, Fathul Mubin, dan Syi 'ir Kanjeng Nabi. Adapun sumber data sekunder untuk mendukung bahasan mengenai tipologi doksologi adalah kitab Serat Burat Arum dan Kitab Bidayatul Hidayah. Peneliti memfokuskan pada tiga manuskrip saja karena dari tiga manuskrip itu mewakili bentuk doksologi yang berada di awal pembahasan. Sedangkan dua manuskrip lainnya merupakan suatu contoh bentuk doksologi yang berada di akhir pembahasan.

Adapun metode analisis yang peneliti gunakan adalah metode deskriptif interpretatif. Peneliti akan mengkategorikan manuskrip yang mempunyai bentuk doksologi yang ada di awal pembahasan dan doksologi yang ada di akhir pembahasan. Dari hasil klasifikasi tersebut, peneliti akan mendiskripsikan secara tekstual bentuk doksologinya. Kemudan, peneliti akan mennginterpretasikan isinya berdasarkan makna dan fungsi penggunaan doksologi tersebut.

\section{HASIL DAN PEMBAHASAN}

Persoalan doksologi diberbagai manuskrip mendapati makna dan fungsi tertentu. Tergantung bagaimana penulis itu mencurahkan pesan puji syukur pada sesuatu yang dianggapnya bagian dari pedoman hidup atau pandangan hidup. Hasyim (2004) mengatakan doksologi berkaiterat dengan kepakaran, latar belakang, serta kedudukan penulis manuskrip. Seperti contoh doksologi di beberapa manuskrip:

\section{Bahjat al-'Ulum Syarah al-Samarqandy ${ }^{1}$}

Bismillāh al-Rahmān al-Rahīm. Rabby yassir wa lā tuassir, al-hamdu li Allāhi al-laży nawwara quīūba al-mu,,minīna bi nūri hidāyatihi. Wa 'as'aluka biriḍ̂ka fi ta' līfi al-

\footnotetext{
1 Bahjat al- 'Ulum mempunyai arti kesenangan ilmu. Sarah (uraian) dari kitab al-Samarqandy. Naskah ini banyak ditemukan dibeberapa daerah dan perpustakaan dibeberapa negara yang menyimpan manuskrip. Dalam pondok pesantren salaf, kitab ini adalah pegangan wajib bagi para santri. Kitab ini penulis temukan di pesantren Miftahul Ulum Pare.
} 
p-ISSN: 2301-5926 | e-ISSN: 2579-793X muḥtașar. Wa al-Șalātu wa al-salāmu alā sayyidina wa mawlānā Muhammadin șalla Alāhu alayhi wa sallāma, wa alā ālihi wa șaḥbihi al-muhājirīna wa al-anșārīna, wa alā al-mu'min̄̄na wa al-mu'mināti min 'ummatihi șalla Allāhu alayhi wa sallām. Wa as'aluka bi syafā'atihi șalla Allāhu alayhi wa sallām, li man yaḥtāju ilā altalabi min țalabi al-mațlūbi allati alfaytu bihā wa sammaytuhā bi bahjati al-ulūm fi 'sy-syarhi fi bayāni aqli al-'umūri.

\section{Terjemahan:}

Dengan menyebut nama Allah yang Maha Pengasih Maha Penyayang. Wahai Tuhanku, mudahkanlah dan janganlah engkau persulit. Segala puji bagi Allah yang telah menerangi hati orang-orang mukmin dengan cahaya hidayah-Nya. Hamba memohon dan berharap atas segala keridaan-Mu dalam menyusun ringkasan ini. Salawat dan salam senantiasa tercurah bagi Nabi dan pemimpin kita, Muhammad SAW, bagi keluarganya dan sahabatnya dari golongan Muhajirin dan dari golongan Anshar, juga bagi orang-orang mukmin laki-laki-perempuan yang selalu patuh kepada-nya. Hamba selalu memohon syafaat-nya bagi orang yang membutuhkan-nya. Hamba menulis dan menamainya Bahjat al-'Ulŭm dalam menjelaskan dan menafsirkan segala sesuatu secara rasional.

\section{Fathu al-Mubin fi Syarhi Ummi al-Barahin ${ }^{2}$}

Bismi Allāhi alrahmāni alrahīm, wa bih̀̄ nasta'̄̄nu. Alhamdu li Allāhi alladz̄̄ anthaqa alkāinaati bi wahdaniyyatin wa ja'ala alsunnata al mawjudata mu'rabatan 'an samaniyyatin. Wa asyhadu an lā ilāha illa Allāhu iqrārun bi rubūbiyyatin, wa asyhadu anna sayyidanā wa nabiyyanā Muhammadan şalla Allāhu 'alaihi wa sallama abduhu wa rasuluhu, alladzi bihi khātama nubuwwatahū wa risālatahu şalla Allahu 'alaihi wa sallam, wa ,, ala alihi wa aşhābihi wa 'isyratihi şalatan wa salaman dāimaini ma qāma zu haqqin burhanu dalili 'aqidatihi

\section{Terjemahan:}

Dengan nama Allah yang Maha Pengasih Maha Penyayang. Hanya kepada-Nya kami memohon pertolongan. Segala puji bagi Allah yang telah menjadikan seluruh ciptaan berbicara tentang keesaan dan menjadikan hukum alam berbicara tentang diamnya. Saya bersaksi tidak ada Tuhan selain Allah sebagai ikrar atas rububiyahnya dan saya bersaksi bahwa pimpinan dan pembimbing kami Muhammad, semoga kesejahteraan dan kedamaian tercurah atasnya, sebagai hamba-Nya dan utusan-Nya. yang dengannya berakhirnya kenabian dan kerasulan, juga kepada keluarga dan sahabat-sahabat-nya, şalawat dan salam yang abadi selama pemilik kebanaran menegakkan bukti dan dalil tentang aqidah-nya.

\section{Syair Kanjeng Nabi}

\footnotetext{
${ }^{2}$ Fathu al-Mubin, memiliki arti kunci penjelsan. Kitab ini sarah dari kitab Ummi al-Barahin, arinya induk semua dalil. Karya dari Muhammad bin Yusuf As Sanusi Husaini Al-Maliki. Kitab ini banyak tersebar dibeberapa pesantren salaf dan perpustakaan manuskrip di luar negeri, karena kitab ini juga termasuk kitab pegangan wajib di pesantren salaf. Kitab ini penulis temukan di pesantren Miftahul Ulum Pare, tetapi penulis juga menemukan disalah satu bekas pesantren kuno di Jombang.
} 
p-ISSN: 2301-5926 | e-ISSN: 2579-793X Ibtidai miwiti ingsun, muji ing Allah kelawan nuwun, ikilah syair ing kanjeng Nabi, mula den syair parase Nabi, mula den pikir sarta den titi, bisaha terang kaya kang ngerti, Nabi Muhammad ingkang sinelir, arep den tutur ana ing syair, putera jalere kiyahi Abdullah, pinuteraken ana ing Makkah. Durunge zhahir kanjeng Rasulullah, den tilar sedara den Abdullah, nalika sedaya den Abdullah, iku benere ana Abwa, den sareaken ana Madinah, kari rerandan Dewi Aminah.

Terjemahan:

Dasar untuk memulai menulis, dengan memuji Allah atas dasar meminta, tulisan ini diberi nama syair Nabi Muhammad, makanya syair ini bercerita Nabi bercukur, makanya difikir dan diamati, agar bisa terang (bermanfaat) bagi yang mengerti, Nabi Muhammad yang menikah kembali, dijelaskan juga di dalam syair, anak laki-laki dari Abdullah dilahirkan di Makkah. Sebelum Nabi Muhammad lahir, Abdullah (ayahnya) meninggal dunia, Abdullah meninggal, dimakamkan di Abwa, tepatnya dikubur di kota Madinah, Dewi Aminah akhirnya menjanda

Doksologi itu adalah sebagai contoh kecil awal mula teks terbentuk dimulai dengan teks puji-pujian kepada Tuhan yang dianggap paling mempunyai peranan penting. Dalam manuskrip berbahasa Arab di semua pesantren tidak ada satupun manuskrip yang ditemui menghilangkan unsur teks doksologi. Teks pujian sebagai teks pengantar wajib. Hasyim (2004) meneliti beberapa manuskrip Islam mencatat, bahwa doksologi itu mempunyai beberapa kegunaan, antara lain:

a. Menandakan rasa bersyukur, mendapatkan keberkatan, dan petunjuk dari Allah SWT. Di samping mendapatkan ganjaran yang baik atas selawat yang kita sampaikan kepada Nabi Muhammad SAW.

b. Untuk menunjukkan identitas manuskrip; manuskrip agama, hukum, hikayat, kesusastraan, dan sebagainya.

c. Untuk menunjukkan latar belakang pendidikan penulis.

d. Menjadi salah satu bukti pengukuhan manuskrip berkenaan sebagai manuskrip tunggal atau asli.

e. Doksologi manuskrip agama mencerminkan bahwa isi kandungan terhindar dari pada unsur mitos dan legenda.

f. Kehadiran doksologi dalam dapatan kajian ilmu atau buku merupakan suatu perjanjian dan pegangan bahwa setiap apa yang kita kemukakan dalam kajian atau buku itu merupakan dapatan yang dipertanggungjawabkan, dan mempunyai manfaat kepada khalayak. 
Pemakaian doksologi dalam buku atau manuskrip (naskah) Islam terletak di bagian mukadimah, berisi puji-pujian. Dalam tradisi manuskrip aksara Jawa sebelum datangnya Islam juga merupakan suatu kewajiban rasa hormat. Tentu saja kepada siapa yang kedudukannya dan kekuasaannya di atas kedudukan dan kekuasaan manusia termasuk penulis sendiri (Dojosantoso, 1986: 21). Kebiasaan ini juga karena sebagai ungkapan doa penulis (pengarang) sebagai rasa syukur dan doa agar karya yang ditulisnya mendapatkan manfaat lebih bagi khalayak, termasuk permulaan doa supaya tidak ada halangan di awal permulaan menulis sampai selesainya penulisan.

Sementara itu Krsono H. Saputra dkk. (2010) menyebut doksologi naskah-naskah pesisiran dengan istilah manggala atau mukadimah, yaitu berisi informasi mengenai halhal yang berkaitan dengan penulisan teks dan kontruksi gramatikal, seperti sun amiwiti amuji, anebut namaning sukma... (aku memulai dengan menyebut nama Hyang Suksma). Padahal menurut Dojosantosa manggala (istilah sastra Jawa kuno) memiliki arti pemimpin atau pelindung. Manggala mengarah pada raja yang dimintai doa restu, bukan teks kalimat mukadimah. Perbedaan antara keduanya sangat tipis, kalau mukadimah mempunyai persamaan arti dengan kata purwastrotra dan doksologi merujuk pada kalimat-kalimat pujian (harapan), sedangkan manggala merujuk pada yang dipuji.

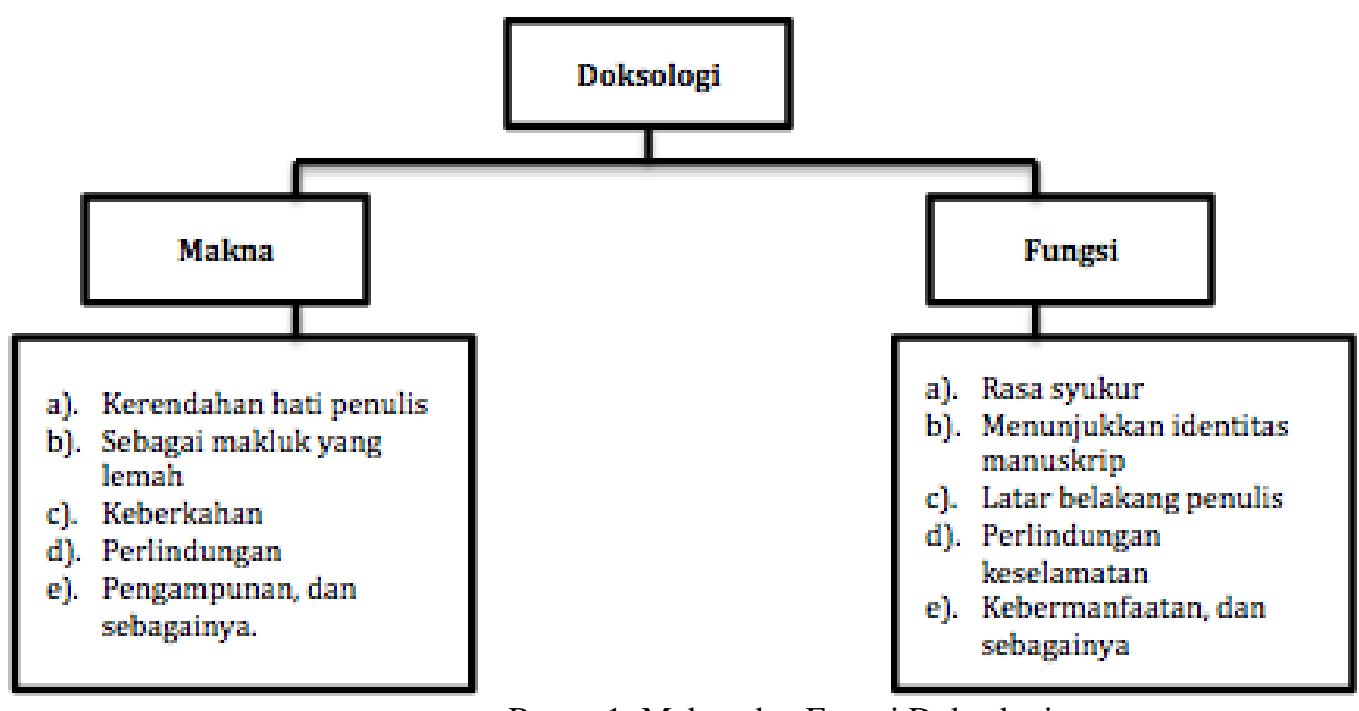

Bagan 1: Makna dan Fungsi Doksologi

Selajutnya Dojosantoso (1986) menambahkan, ucapan dan pujian tersebut ditujukan kepada Hyang Tunggal. Sebab pujangga yakin bahwa tanpa pengayoman dari Tuhan yang Maha Esa, pekerjaannya tidak akan berjalan lancar. Sehingga dalam beberapa 

pujangga karya-karya kuno di permulaan teks selalu memakai kata Awighnam astu, Om awinghnam astu nammas siddam. Kata itu tidak bermaksud formalitas, tetapi memang pedoman keyakinan yang paling mendalam. Seperti apa yang terdapat pada:

1. Kakawin Ramayana ${ }^{3}$

$$
\text { SANG DACARATHA }
$$

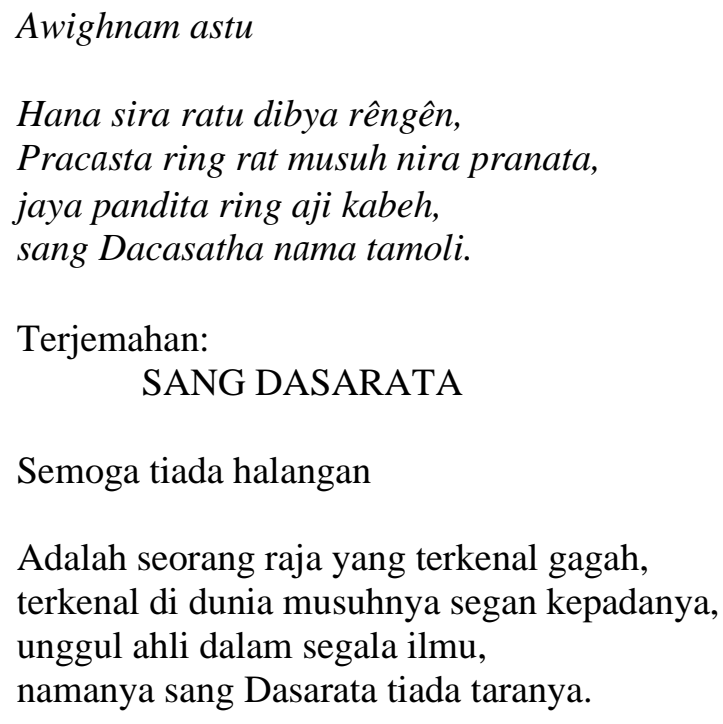

2. Kakawin Bharatayuddha ${ }^{4}$

\section{Awighnam astu}

Sang curamrih ayajnya ring samara mahyun i hilanganikang parangmuka, lila kêmbang ura sekar taji ni kecaning ari pêjah ing rananggana, urnna ning ratu mati wijanira kundanira nagaraning musuh gêsêng, sahityahuti têndasing ripu kapokan i ratha nika sucremeng laga

Terjemahan:

Sang pahlawan ingin bersaji di medan perang dan bertujuan untuk membinasakan musuhnya, yang merupakan taburan bunga yang indah adalah untaian bunga di atas rambut yang gugur di medan perang, urna hiasan menikam di dahi raja yang telah meninggal merupakan beras persajian, negara musuh yang terbakar adalah tempat api persajian, yang disajikan ialah kepada musuh yang telah terpenggal di atas keretanya setelah bertempur tidak mengenal mundur di medan perperangan.

\footnotetext{
3 Dr Soewito Santoso. 1973. Lilaracana-Ramayana Jilid I. Yogyakarta: Gajah Mada University Press, dalam Dojosantosa, hal. 19.

${ }^{4}$ Prof. Dr. R. M Soetjipto Wirjosoeparto. 1968. Kakawin Bharatayudha. Jakarta: Bhratara, dalam Dojosantosa, hal. 20.
} 
p-ISSN: 2301-5926 | e-ISSN: 2579-793X

Dalam doksologi Kakawin Ramayana menunjukkan pujian pada sang raja yang disanjung karena kegagahan, kuat, dan ahli dalam segala ilmu (pintar) tiada tandingan. Sedangkan Kakawin Bharatayuddha menawarkan sebuah harapan atau doa agar tetap semangat dan tidak mundur menghadapi musuh. Ini sebagai harapan sang pujangga kepada raja yang sangat dihormati agar tidak ada suatu rintangan.

Kalimat-kalimat doksologi itu letaknya tidak hanya di awal teks namun terkadang terdapat pada akhir teks. Antara awal teks dan akhir teks kalimatnya berbeda, tergantung pujangga atau penyalin naskah. Sering juga kita menemukan teks doksologi naskahnaskah keagamaan yang mendapatkan tambahan dari pribadi sang penyalin, tertera pada kolofon. Teks itu berupa doa dan harapan semoga Allah memberikan ampunan saat melakukan penyalinan, seperti pada kolofon teks naskah Bidayatul Hidayah. ${ }^{5}$

Gafarallahu lana bisawabi wa al-khata'i fi al-mazydi al-hurufi wa nuqsani fi al-hurufi fi gaflana fi mali'i fiddunya gafarallahu lana fa inlam tagfir lanakunanna minal khasirin allahumma inni 'audzubika min an yabgada li min ahlisi.

Terjemahan:

Semoga Allah mengampuni dengan pahala dan atas kesalahan penambahan huruf dan kekurangan dalam huruf, dalam kesalahan saya di dunia. Dan semoga Allah mengampuni kita, jika Allah tidak mengampuni maka saya (penyalin) termasuk orang yang rugi. Ya Allah saya berlindung kepada engkau dari kebencianmu terhadapku dengan ikhlas

\footnotetext{
5 Naskah ini koleksi Agus Sulton. Memakai kertas Eropa. Terdiri atas 129 lembar atau 257' halaman. Lembar pertama berada di depan jilidan kertas merang. Untuk penomoran yang penulis gunakan adalah mulai dari lembar pertama kertas Eropa. Halaman 1,2 3, 5, 8, 9, 245, 247, 248, 251, 252, 253, 254, 255, 256, 257= berupa coretan dan catatn kaki memakai tinta hitam, tinta merah dan pensil. Halaman 1 catatan kaki berupa doa, terdiri atas 4 baris dikuti coretan pensil. Halaman 2 berisi doa doa tolak tahun terdiri atas 6 baris. Halaman 3 catatan pensil pegon. Halaman 5 dan 8 tinta hitam coretan dan catatan doksologi awal teks. Halaman 9 berupa catatan tanggal lahir dan weton 11 baris, pegon berharakat. Halaman 245 catatan kaki bahasa Arab makna gandulan terdiri atas 6 baris. Halaman 247 catatan kaki tinta hitam berbahasa Arab, yaitu nadam terdiri atas 8 baris, sedangkan halaman 248 hanya 1 baris sebagai lanjutan dari halaman sebelumnya. Halaman 251 ada 6 baris memakai tinta hitam bahasa Arab dan makna gandulan. Halaman 252, $253,254,255,256=8$ baris ditulis terbalik, memakai tinta hitam dan merah. Halaman 257 ada catatan kaki pegon tinta hitam tidak berharakat, menjelaskan mengenai waktu penyalinan naskah ini. Jumlah halaman yang tidak tertulis (kosong) $=4,6,7,10,11,246,249,250$. Di dalam naskah ini terselip 5 lembaran; dua lembar kosong, dan tiga lembar berupa surat pribadi memakai aksara pegon. Jumlah kurasnya ada 8 . Ukuran lembar naskah panjang $20,5 \mathrm{~cm}$, lebar 17 $\mathrm{cm}$. Ukuran ruang teks panjang $14,5 \mathrm{~cm}$, lebar $11 \mathrm{~cm}$ dengan pias atas $3,3 \mathrm{~cm}$, pias bawah $2,7 \mathrm{~cm}$, pias kanan $2 \mathrm{~cm}$, dan pias kiri $4 \mathrm{~cm}$. Teks Bidayatul Hidayah dimulai dari nomor 12-244. Keadaan tulisan naskah ini termasuk sangat jelas bila dibandingkan dengan teks Bahjat Al-Ulum Fi Sharh Aqidat Al-Usul. Lubang bekas dimakan rayap tidak ditemukan pada kertas Eropa, hanya lepas dari jilidannya pada halaman 236-257 akibat sampul bagian belakang berlubang dimakan rayap. Teks Bidayatul Hidayah karya Abu Hamid Muhammad Al-Ghazali diterbitkan pertama kali oleh Syarikah Daar Haafidz lin-Nasyr wat-Tauzi, Jedah Cet. I Tahun 1992 M. Sebelum tahun itu teks naskah hanya berbentuk tulisan tangan. Kandungan teks menjelaskan mengenai perikalu tazkyatun nufus atau adab dalam berkehidupan, seperti cara bersikap kepada orang tua, kepada orang lain, termasuk aturan sebelum tidur, waktu tidur, ke kamar madi, dan beberapa macam berbuatan mungkar disertai ancama kelak di akhirat.
} 
Selain doksologi dari penyalin naskah. Pengarang kitab di akhir teks memberikan pujian kepada Allah sebagai pelindung jagat raya, maha segala-galanya. Di hampir semua naskah keagamaan pasti mempunyai doksologi pada akhir teks naskah. Seperti akhir teks Bidayatul Hidayah:

Rabbi al-alamin wa sallamu 'aikum wa rahmatullahi wa barakatuh wa al-hamdulillahi 'awwal wa akkhir wa dahiran wa batinan wala haula wala quwwata illa billahi al-aliyi al-adzim.

Terjemahan:

Allah yang maha kuasa terhadap alam semuanya dan keselamatan atas kamu (pembaca) dan kehormatan Allah dan berkahnya, dan puji bagi Allah dzat yang paling awal-akhir dhohir dan batin. Dan tidak ada kekuatan selain Allah yang Maha Tinggi lagi Maha Agung.

Hal ini juga berlaku pada sastra Jawa, seperti pada Serat Burat Arum: ${ }^{6}$

Sagung narapraja den taberi, Mardi mring wewengkon, linulusna rahayuning tyase, Mrih lumintu kamulyaning nagri, Ayem den ayomi, Wahyuning Hyang Agung.

Terjemahan:

Seluruh punggawa negara supaya rajin, membangun daerahnya, semoga baik hatinya agar negerinya selalu mulia, tenteram diayomi oleh wahyunya Hyang Agung.

Doksologi intinya adalah harapan, pengayoman dari Tuhan, dan orang-orang yang dianggap sangat berjasa. Menurut Dojosantosa (1985: 24) dalam sastra Jawa kuno doksologi ini sebagai pertanda kereligiusan seseorang dan sikap rendah hati mengingatkan diri kepada Tuhannya dengan tujuan agar mendapat pengayoman itu sungguh-sungguh meyakinkan. Tidak hanya sekedar diwujudkan dengan kata-kata saja tetapi diciptakan pula bentuk lambang yang maknanya senada. Jadi tidak hanya sekedar menalurikan apa yang telah diwariskan oleh sastra Jawa kuno tetapi kemudian dikembangkan sesuai dengan daya cipta yang dimilikinya.

Namun, dalam perkembangan di era modern sekarang doksologi tidak hanya tertuju pada Tuhan, para Nabi, dan Rosul tetapi bentuk pujian ini sudah mulai berkemban kepada orang-orang yang dianggap berjasa dalam proses penyusunan atau penulisan. Orang-orang ini bisa jadi hidup pada ruang lingkup pimpinan, lembaga, sahabat, dan keluarga. Secara personal, doksologi merupakan cermin atas sikap religius seseorang, sikap toleransi, kebersamaan, mengasihi sesama, dan intelektualitas manusia.

\footnotetext{
${ }^{6}$ Raden Bhratakesawa. 1928. Burat Arum. Kediri: Tan Khoen Swie, dalam Dojosantosa hal. 26.
} 


\section{E. KESIMPULAN}

Doksologi merupakan bahasa Yunani yang mempunyai persamaan dengan kata purwastrotra, mukadimah, dan manggala. Pengertian doksologi lebih diprioritaskan sebagai bentuk pujian-pujian yang terdapat dalam awal manuskrip atau akhir manuskrip. Hal ini dianggap penting disamping sebagai gaya akan sebuah hasil karya yang tidak monoton tetapi untuk penulisnya mempunyai tujuan lain, yakni bentuk pujaan-pujaan, sanjungan, ucapan terimakasih dengan harapan berhati bangga dan memohon perlindungan agar teksnya bermanfaat bagi para pembaca dan pada saat proses penyalinan atau memproduksi naskah tidak mengalami kendala.

Dalam tradisi tulis masyarakat modern sekarang, doksologi masih dimanfaatkan dan mempunyai peranan penting atas keberlangsungan kerja penelitian. Penggunaan doksologi yang dulunya ditekankan pujian-pujian terhadap sesuatu yang bersifat dogmatis, di era sekarang berkembang ke ruang lingkup pimpinan, lembaga, sahabat, dan keluarga. Dengan demikian, doksologi sebagai bentuk etika dan ekspresi atas manusia yang beradab dalam menghasilkan kekaryaan teks tulis. Dari doksologi pula tercermin sikap religius, toleransi, kebersamaan, mengasihi sesama, dan intelektualitas manusia.

\section{F. SARAN}

Penelitian ini hanya mengidentifikasi beberapa manuskrip untuk dijadikan sampel dalam melihat karakter doksologi disertai makna dan fungsi. Penelitian ini masih sangat jauh dari sempurna, karena penelitian ini hanya sekedar pengantar awal menyoal doksologi. Selama ini, penelitian doksologi kurang menjadi perhatian oleh para peneliti di bidang manuskrip padahal melalui doksologi pula identitas sosial seorang penulis, psikologi, religiusitas, dan identitas budaya seorang dapat fahami. Oleh karena itu, semoga ke depan ada peneliti yang punya perhatian di bidang psikologi untuk melihat identitas penulis melalui sudut pandang doksologi.

\section{DAFTAR PUSTAKA}

Clear, James. 2018. Atomic Habits. New York: Penguin Random House. 
p-ISSN: 2301-5926 | e-ISSN: 2579-793X

Dipodjojo, Asdi S. 1986. Kesusastraan Indonesia Lama Pada Zaman Pengaruh Islam. Yogyakarta: Lukman

Dojosantosa. 1985. Unsur Religius Dalam Sastra Jawa. Semarang: Aneka Ilmu.

Hashim Bin Haji Abd. Hamid, Haji. 2004. Doksplogi Dalam Manuskrip. Makalah Seminar Manuskrip Islam. Pusat Persidangan Antarbangsa Negara Brunei Darussalam.

Saputra, Karsono H, dkk. 2010. Naskah-Naskah Pesisiran. Jakarta: PNRI

Schaik, Carel van dan Kai Michel. 2016. The Good Book of Human Nature: An Evolutionary Reading of the Bible. New York: Basic Books.

Mazhahiri, Allamah Husain. 2002. Rahasia Doa. Bogor: Cahaya.

Puar, Yusuf Abdullah. 1984. Masuknya Islam Ke Indonesia. Jakarta: CV Indradjaya. 